\title{
Serum Cytosolic $\beta$-Glucosidase Activity in a Rat Model of Necrotizing Enterocolitis
}

\author{
REED A. DIMMITT, ROBERT GLEW, CHRISTOPHER COLBY, MARY BRINDLE, \\ ERIK SKARSGARD, AND R. LAWRENCE MOSS
}

Department of Pediatrics, University of Alabama at Birmingham, Birmingham, Alabama 35233, U.S.A.

[R.A.D.], Department of Biochemistry, University of New Mexico, Albuquerque, New Mexico 87131,

U.S.A. [R.G.], Department of Pediatrics [C.C.], Department of Surgery [M.B., E.S.], Stanford University, Palo Alto, California 94304, U.S.A., and Department of Surgery, Yale University, New Haven,

Connecticut 06520, U.S.A. [R.L.M.]

\begin{abstract}
The diagnosis of necrotizing enterocolitis (NEC) is made
from a combination of clinical and radiographic findings. There
are no useful screening biochemical markers of intestinal injury.
The serum concentration of cytosolic $\beta$-glucosidase (CBG), an
enzyme found primarily in enterocytes, is markedly elevated in
animal models of ischemia and bowel obstruction. We hypoth-
esized that in a rat model of NEC, serum CBG activity would
significantly increase before microscopic evidence of severe
intestinal injury. Cohorts of 2 -wk-old Sprague-Dawley rats ( $n=$
10/cohort) were anesthetized and underwent laparotomy with
occlusion of the superior mesenteric artery (SMA). Platelet-
activating factor (200 $\mu \mathrm{g}$ /animal) was injected in the proximal
duodenum. Serum and intestinal samples were obtained at time 0
(control) and 30,60 , and 90 min of ischemia (I) and after 90 min
of I followed by 60 min of reperfusion (I/R). Histopathologic
injury was categorized as either no or minimal injury or mural
necrosis by two masked investigators and CBG activity was
\end{abstract}
A recent study from the National Institute of Child Health and Human Development (NICHD) Neonatal Research Network reported the incidence rate of NEC was $9 \%$ in infants with a birthweight of 751-1000 $\mathrm{g}$ and increased to $14 \%$ in those babies weighing 501-750 g (1). The odds ratios of death for patients with NEC has been reported to be 13.9 and 24.5, respectively, compared with similar preterm infants without NEC (2).

One possible explanation for the poor outcomes in babies with NEC is a delay in diagnosis and subsequent therapy. Currently, the diagnosis of NEC is based on clinical and radiographic findings. Once patients are diagnosed with definitive NEC ( $\geq$ Bell's stage 2 ), significant intestinal damage has

Received October 16, 2002; accepted May 6, 2003

Correspondence: Reed A. Dimmitt, M.D., Department of Pediatrics, Division of Neonatology, University of Alabama at Birmingham, 525 New Hillman Building, 619 19th Street South, Birmingham, AL 35233, U.S.A.; e-mail: rdimmitt@peds.uab.edu

DOI: 10.1203/01.PDR.0000081310.47579.49 measured by ELISA. Data were analyzed with Fisher's exact test and ANOVA. Only the I/R group had significantly greater mural necrosis compared with the control group ( $90 \%$ versus $0 \%$, respectively, $p<0.001)$. In contrast, $\mathrm{CBG}$ activity was significantly elevated after only $90 \mathrm{~min}$ of I and after I/R (15.1 \pm 5.6 and $16.4 \pm 4.3$ units $/ \mathrm{mL}$, respectively, $p<0.05$ ). We conclude that serum $\mathrm{CBG}$ is elevated before transmural intestinal injury in this model and may have utility as an early marker of ischemia in patients at risk for NEC. (Pediatr Res 54: 462-465, 2003)

Abbreviations
NEC, necrotizing enterocolitis
CBG, cytosolic $\beta$-glucosidase
SMA, superior mesenteric artery
PAF, platelet activating factor
I, ischemia
I/R, ischemia/reperfusion

likely occurred (3). It is possible that earlier detection of intestinal injury and institution of appropriate treatment might prevent the progression of disease.

Morris et al. (4) reported that $\mathrm{CBG}$, an enzyme found in intestinal epithelial cells, was elevated in adult guinea pigs in early ischemic and closed-loop occlusion intestinal injury. Although CBG was present in several organs, the small intestine had by far the greatest activity.

The aim of our study was to test the hypothesis that serum levels of $\mathrm{CBG}$ would be elevated in a juvenile rat model of NEC. Additionally, because CBG is found in intestinal epithelial cells, this elevation would occur before microscopic evidence of severe intestinal injury when the damage could be reversible.

\section{METHODS}

Animals. The experimental protocol was approved by the Administrative Panel on Laboratory Animal Care of Stanford 
University in conjunction with the Association for Assessment and Accreditation of Laboratory Animal Care guidelines.

A modification of the model of intestinal ischemia described by Musemeche et al. (5) was used. Two-week-old SpragueDawley rats (Charles River Laboratories, Wilmington, MA, U.S.A.) were anesthetized with isoflurane (Baxter Pharmaceuticals, Thousand Oaks, CA, U.S.A.). After a midline ventral laparotomy, the SMA was identified. A microaneurysm clip was placed across the SMA and $200 \mu \mathrm{g}$ of PAF (Sigma Chemical, St. Louis, MO, U.S.A.) was injected into the proximal duodenum. The peritoneal cavity was lavaged with lactated Ringer's solution warmed to $37^{\circ} \mathrm{C}$ and the abdominal was closed with 4-0 silk suture. Cohorts of 10 animals underwent varied duration of I: 0 (control), 30, 60, and $90 \mathrm{~min}$. The control animals were killed immediately after closing the abdominal wall, approximately $3 \mathrm{~min}$ after the injection of PAF. Another cohort of 10 animals had $90 \mathrm{~min}$ of ischemia after which the clip was removed for $60 \mathrm{~min}$ of reperfusion (I/R). After completing the duration of intestinal injury, the rats were killed with an overdose of intraperitoneal pentobarbital $(100 \mathrm{mg} / \mathrm{kg})$. Blood was sampled by cardiac puncture and the serum harvested after centrifugation was stored at $-80^{\circ} \mathrm{C}$. Sections of mid-ileum were placed in $10 \%$ buffered formalin for microscopic analysis.

Microscopic injury score. Paraffin sections of ileum were processed and stained with hematoxylin-eosin. Two masked investigators assessed intestinal injury using the following scoring criteria: $0=$ no diagnostic changes, $1=$ partialthickness mucosal damage, 2 = full-thickness mucosal damage, 3 = partial-thickness muscularis necrosis, $4=$ full bowel wall necrosis (Fig. 1). A score of $0-2$ was categorized as no or minimal injury and a score of 3-4 was labeled mural necrosis for statistical analysis.

CBG determination. Serum CBG activity was determined by an end-point fluorometric assay previously described by one of the authors (6). Five microliters of serum was added to the assay medium containing $0.2 \mathrm{M} \mathrm{Na}$ citrate, $\mathrm{pH} 6.0$, and $5 \mathrm{mM}$ 4-methylyumbelliferyl- $\beta$-D-glucopyranoside in a final volume of $0.1 \mathrm{~mL}$. The enzymatic reactions were incubated at $37^{\circ} \mathrm{C}$ for $30 \mathrm{~min}$ and terminated by the addition of $2.9 \mathrm{~mL}$ of $0.3 \mathrm{M}$ ammonia glycine buffer, $\mathrm{pH}$ 10.0. The fluorescence of the product of the reaction, 4-methylumbelliferone, was measured using a Turner model 450 fluorometer (Turner Instruments, Sequoia, CA, U.S.A.) with a band pass $360-\mathrm{nm}$ excitation filter

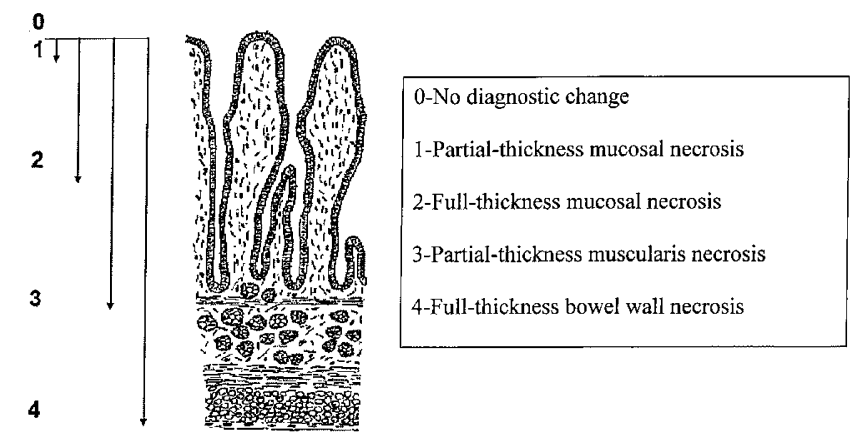

Figure 1. Histopathologic criteria used for microscopic injury scores. Adapted from Musemeche et al. (5). and a sharp cut 515-nm emission filter. One unit of enzyme activity was defined as $1 \mathrm{nmol}$ of product per hour.

Statistical analysis. SigmaStat for Windows software (SPSS Inc., Chicago, IL, U.S.A.) was used for statistical analysis. The individual injury scores of each group were compared using the Mann-Whitney ranked sum test. Categorical differences (no or minimal injury versus mural necrosis) in microscopic intestinal injury were analyzed using Fisher's exact test. The mean serum CBG activity $\pm \mathrm{SD}$ was evaluated with ANOVA. Statistical significance was defined as $p<0.05$.

\section{RESULTS}

There were no premature deaths (defined as not surviving until completion of the study period) in any of the groups. After euthanasia, the macroscopic appearance of injury was uniform throughout the distal ileum.

Histopathologic injury. Sections of ileum from the five groups revealed injury from a score of 0 (no diagnostic change) to 4 (full-thickness bowel wall necrosis) (Fig. 2). The median
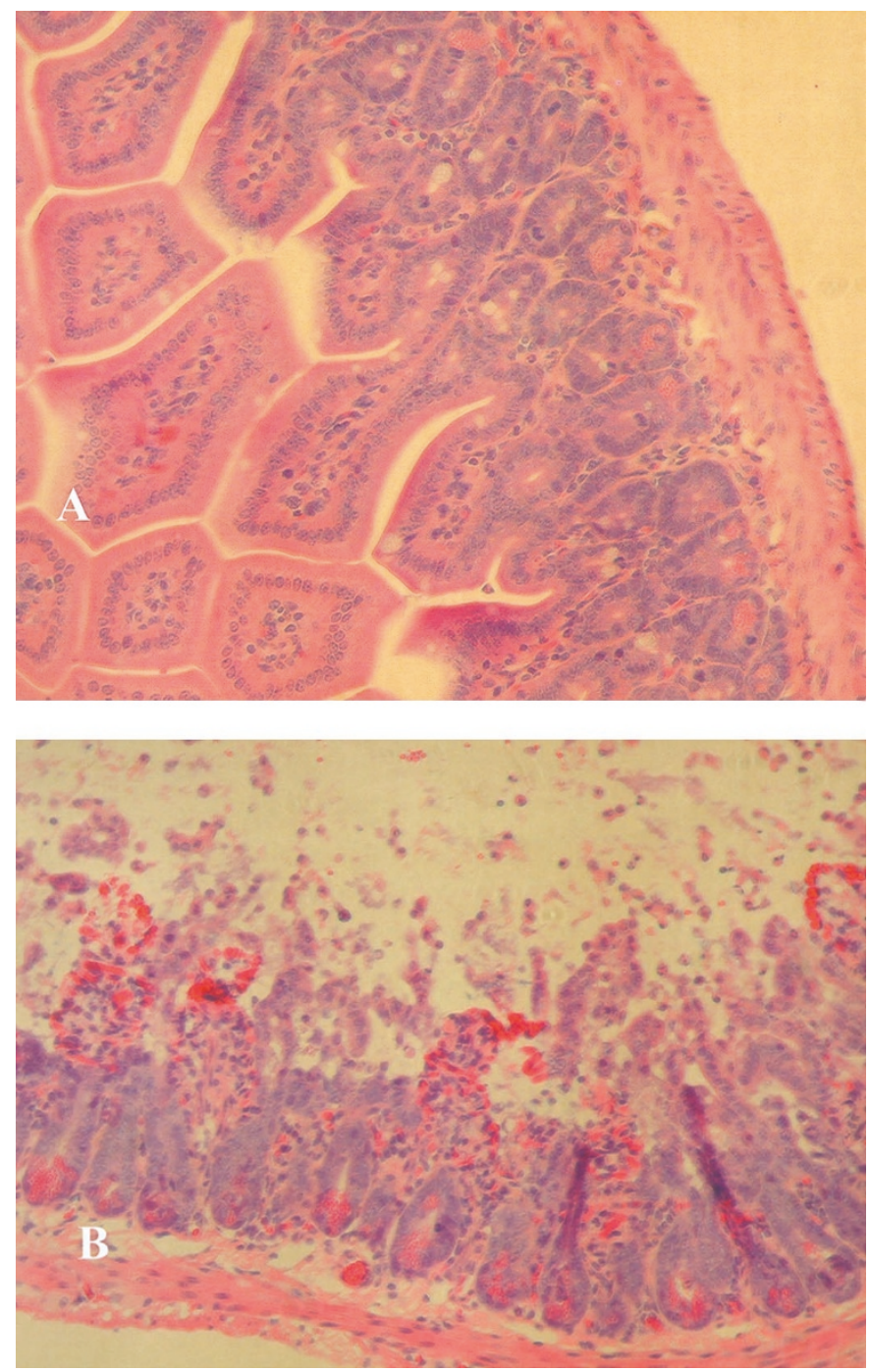

Figure 2. Representative histology used for microscopic injury scoring. (A) A section of ileum with no or minimal injury. $(B)$ A section of ileum with mural necrosis. 
injury score of each group was significantly greater than the control group (Table 1). There was no difference in the percentage of animals with mural necrosis between the control group and the groups undergoing only I. Even after 90 min of I, only one animal had severe intestinal injury. Only the rats that underwent both prolonged I and subsequent reperfusion had significant injury. Compared with the control group, there was more mural necrosis in the $\mathrm{I} / \mathrm{R}$ group ( $0 \%$ versus $90 \%$, respectively, $p<0.001$ ) (Fig. 3).

Serum CBG activity. The baseline serum CBG activity was $8.86 \pm 1.8$ units $(\mathrm{U}) / \mathrm{mL}$, representing the contributions of the sham laparotomy and PAF administration in the control animals (Fig. 4). In contrast to microscopic injury, serum CBG activity increased to a significant level after only 90 min of I and remained elevated in the $\mathrm{I} / \mathrm{R}$ group $(15.13 \pm 5.64$ and $16.41 \pm 4.30 \mathrm{U} / \mathrm{mL}$, respectively, $p<0.05)$. Thus, there was cellular damage with leakage of $\mathrm{CBG}$ before microscopic evidence of mural necrosis. When analyzed by categorical injury score, the serum CBG activity was significantly greater in the mural necrosis group $(17.03 \pm 2.8 \mathrm{U} / \mathrm{mL})$ compared with the no or minimal injury group $(10.8 \pm 2.6 \mathrm{U} / \mathrm{mL} p<$ $0.05)$.

\section{DISCUSSION}

In our study, we found that elevated serum CBG activity preceded microscopic evidence of severe intestinal injury. This finding is in agreement with previous reports describing the rapid rise of serum $\mathrm{CBG}$ after ischemic injury $(4,7,8)$. In addition, Morris et al. (4) found a rapid rate of rise of serum CBG in animals undergoing intestinal ischemia and concluded that other organs expressing CBG did not contribute significantly to serum CBG activity. They demonstrated that CBGspecific activity in the combined intestinal compartments (duodenum, jejunum, ileum, and cecum) was approximately 6,000 $\mathrm{U} / \mathrm{mg}$, contributing to more than $80 \%$ of the total organ expression of CBG. Thus, in this animal model of NEC, the elevation in serum CBG likely resulted from intestinal injury.

This animal model of NEC closely mimics the type of vascular compromise that occurs in adult human ischemic intestinal injury. Several studies in the adult literature suggest that a sensitive screening test would assist clinicians in the diagnosis of intestinal ischemia, allowing earlier therapeutic intervention with improved survival (9-11). Currently, no such test is available for either adult or neonatal intestinal injury.

Our study suffers from the same limitation as other models of NEC. All existing models are based on some type of deliberate intestinal manipulation used to reproduce a histo-

Table 1. Comparison of mean intestinal injury scores after varying durations of ischemia (I) and reperfusion (R)

\begin{tabular}{ccc}
\hline Group & Median injury score & $P$ value* $^{*}$ \\
\hline Control & 0 & - \\
30 min I & 1 & 0.003 \\
60 min I & 1 & 0.001 \\
90 min I & 2 & 0.001 \\
I/R & 3 & 0.001
\end{tabular}

All groups with $n=10$.

* Comparison to control group using Mann-Whitney rank sum test.

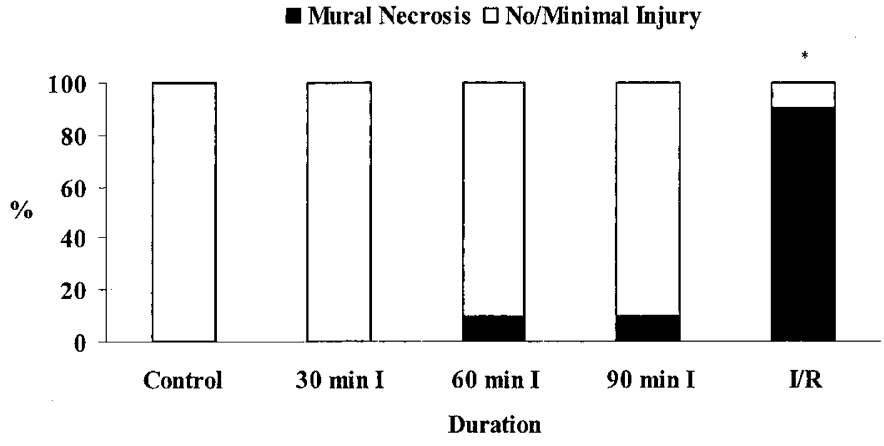

Figure 3. Percentage of rats with either no or minimal injury or mural necrosis by duration of ischemia. A microscopic injury score of $0-2$ was defined as isolated mucosal injury and scores of 3-4 as mural necrosis. Only the I/R group had significantly greater injury than the control group. ${ }^{*} p<0.05$.

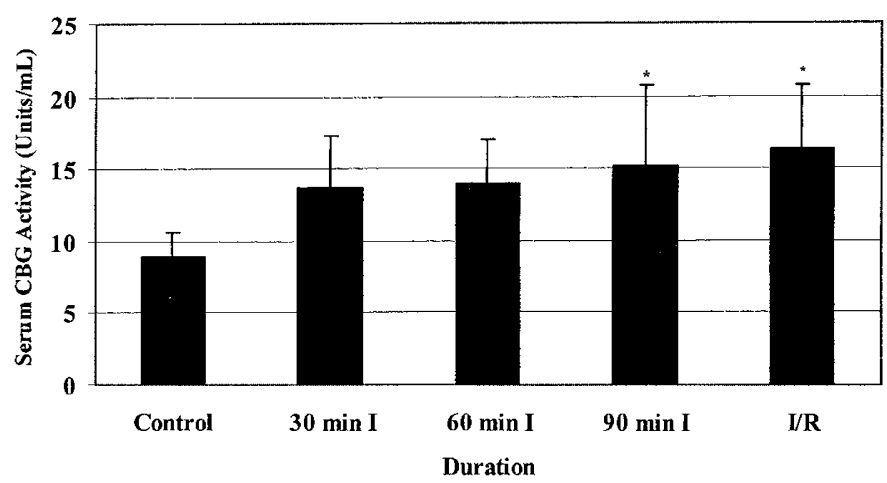

Figure 4. Serum CBG activity (expressed as mean \pm SD) by duration of ischemia. Both the $90 \mathrm{~min}$ of I and the I/R groups had significantly elevated serum CBG activity compared with the control group. ${ }^{*} p<0.05$.

logic injury similar to that seen in human NEC. However, the histologic findings in NEC are nonspecific and similar to that seen after a variety of ischemic and injured states. Most proposed animal models of NEC use some form of ischemia/ hypoxemia with subsequent reperfusion, but the mechanism of naturally occurring human NEC is more complex $(12,13)$. Still, the likely final common pathway is epithelial damage followed by translocation of bacteria and endotoxins, which results in a cascade of molecular and cellular reactions resulting in dead bowel. A screening tool for potentially reversible intestinal injury may allow the earlier therapeutic intervention in neonatal patients as well.

Several serum markers have been proposed as screening tests for intestinal ischemia. Early reports suggested using the serum levels of lactate dehydrogenase, alkaline phosphatase, creatine kinase, and the hepatic transaminases to predict intestinal infarction (14-16). All of these potential enzyme markers had both poor sensitivity and specificity. More recently, the circulating levels of IL-1ra, IL-6, IL-8, IL-10, thrombopoietin, acute phase reactants, C-reactive protein, and orosomucoid have all been suggested as possible biochemical markers of NEC (17-20). These markers suffer from both poor sensitivity and specificity and are elevated only in severe NEC. They may provide no greater utility in detecting early NEC than traditional clinical findings. 
Pursuant to these findings in animals, we plan next to measure the serum CBG activity in patients with NEC. We will first compare serum CBG levels of age-matched control patients with those of patients with NEC. If we observe a significant difference, we could then determine whether there is a threshold that could help differentiate patients with mild NEC that will resolve without aggressive therapy from those with severe NEC. The first studies are currently underway and we await the results of these measurements.

\section{REFERENCES}

1. Lemons JA, Bauer CR, Oh W, Korones SB, Papile LA, Stoll BJ, Verter J, Temprosa M, Wright LL, Ehrenkranz RA, Fanaroff AA, Stark A, Carlo W, Tyson JE, Donovan EF, Shankaran S, Stevenson DK 2001 Very low birth weight outcomes of the National Institute of Child health and human development neonatal research network, January 1995 through December 1996. NICHD Neonatal Research Network. Pediatrics 107:E1

2. Bisquera JA, Cooper TR, Berseth CL 2002 Impact of necrotizing enterocolitis on length of stay and hospital charges in very low birth weight infants. Pediatrics 109:423-428

3. Bell MJ, Ternberg JL, Feigin RD, Keating JP, Marshall R, Barton L, Brotherton T 1978 Neonatal necrotizing enterocolitis: therapeutic decisions based upon clinica staging. Ann Surg 187:1-7

4. Morris S, Hays W, Enomoto M, Glew R, Feddersen R, Fry D, Morris D 1999 Serum cytosolic beta-glucosidase elevation and early ischemic injury to guinea pig small intestine. Surgery 125:202-210

5. Musemeche CA, Baker JL, Feddersen RM 1995 A model of intestinal ischemia in the neonatal rat utilizing superior mesenteric artery occlusion and intraluminal plateletactivating factor. J Surg Res 58:724-727
6. Peters SP, Lee RE, Glew RH 1975 Differentiation of $\beta$-glucocerebrosidase from $\beta$-glucosidase in human tissues using sodium taurocholate. Arch Biochem Biophys 175:569-582

7. Chang CT, Imai K, Chang YC, Hayashi T, Kohno H, Nagasue N, Nakamura T 1991 Plasma lysosomal enzymes after liver transplantation in the pig. Enzyme 45:145-154

8. Liu W, Schob O, Pubmire JE, Jackson DE, Zucker KA, Fry DE, Glew RH 1996 Glycohydrolases as markers of hepatic ischemia-reperfusion injury and recovery. Hepatology 24:157-162

9. Boley SJ, Sprayregan S, Siegelman SS, Veith FJ 1977 Initial results from an aggressive roentgenological and surgical approach to acute mesenteric ischemia. Surgery $82: 848-855$

10. Kaleya RN, Sammartano RJ, Boley SJ 1992 Aggressive approach to acute mesenteric ischemia. Surg Clin North Am 72:157-182

11. Heys SD, Brittenden J, Croft TJ 1993 Acute mesenteric ischemia: the continuing difficulty in early diagnosis. Postgrad Med J 69:48-51

12. Caplan MS, MacKendrick W 1993 Necrotizing enterocolitis: a review of pathogenic mechanisms and implications for prevention. Pediatr Pathol 13:357-369

13. Kleigman RM 1998 Pathophysiology and epidemiology of necrotizing enterocolitis. In Polin RA, Fox WW (eds) Fetal and Neonatal Physiology. WB Saunders, Philadelphia, pp 1425-1432

14. Calaman C, Hershey F, Skaggs J 1958 Serum lactate dehydrogenase in the diagnosis of the acute surgical abdomen. Surgery 44:43-51

15. Barnett S, Davidson E, Bradley E 1976 Intestinal alkaline phosphatase and base deficit in mesenteric occlusion. J Surg Res 20:243-246

16. De Toma G, Marzano D, Salvatore P, Cerza F, De Cesare E, Giacovazzo M, Martelletti P, Antonucci M 1983 Enzymatic and metabolic changes in peripheral serum after superior mesenteric artery ligation in dogs. Ital J Surg Sci 13:269-273

17. Edelson MB, Bagwell CE, Rozycki HJ 1999 Circulating pro- and counterinflammatory cytokine levels and severity in necrotizing enterocolitis. Pediatrics 103:766-771

18. Romagnoli C, Frezza S, Cingolani A, De Luca A, Puopolo M, De Carolis MP, Vento G, Antinori A, Tortorolo G 2001 Plasma levels of interleukin-6 and interleukin-10 in preterm neonates evaluated for sepsis. Eur J Pediatr 160:345-350

19. Colarizi P, Fiorucci P, Caradonna A, Ficuccilli F, Mancuso M, Papoff P 1999 Circulating thrombopoietin levels in neonates with infection. Acta Paediatr 88:332 337

20. Isaacs D, North J, Lindsell D, Wilkinson AR 1987 Serum acute phase reactants in necrotizing enterocolitis. Acta Paediatr Scand 76:923-927 